\title{
SLEEVE GASTRECTOMY IN A PATIENT WITH CELIAC DISEASE AND THALLESEMIA MINOR IS SAFE
}

Ramraj V. N1, Tulip Chamany², Ramesh $\mathrm{M}^{3}$

\section{HOW TO CITE THIS ARTICLE:}

Ramraj V. N, Tulip Chamany, Ramesh M. "Sleeve Gastrectomy in a Patient with Celiac Disease and Thallesemia Minor is Safe". Journal of Evolution of Medical and Dental Sciences 2014; Vol. 3, Issue 61, November 13; Page: 13617-13620, DOI: 10.14260/jemds/2014/3817

ABSTRACT: INTRODUCTION: Celiac disease is a chronic small intestinal immune- mediated enteropathy precipitated by exposure to dietary gluten in genetically predisposed individuals. Classical celiac disease presents with signs and symptoms of mal absorption. The true prevalence of the disease is not known. Up to $13 \%$ of patients with celiac disease are overweight. Any abdominal surgery can trigger the disease in a previously normal patient or aggravate the disease. OBJECTIVE: To show that simpler bariatric procedures like sleeve gastrectomy can be performed safely in patients with celiac disease. METHODS: A 53 year old female, a known case of Type II Diabetes mellitus, hypertension, OSA on treatment \& who was diagnosed to have thalassemia minor 24 years back and celiac disease 7 years back, having a BMI of $43.5 \mathrm{~kg} / \mathrm{m}^{2}$ \& HbA1c of $7.3 \%$ underwent laparoscopic sleeve gastrectomy. RESULTS: Patient has had $45 \%$ excess weight loss at one year follow up with complete remission of diabetes (HbA1c of 5.4\%), without any aggravation of celiac disease. CONCLUSION: Sleeve gastrectomy appears to be safe and well tolerated in patients with celiac disease.

KEYWORDS: Celiac disease, immune mediated enteropathy, Thalessemia minor, Sleeve gastrectomy, Diabetes mellitus, remission.

INTRODUCTION: Celiac disease is a chronic small intestinal immune-mediated enteropathy precipitated by exposure to dietary gluten in genetically predisposed individuals.[1] Classical celiac disease usually presents with signs and symptoms of mal absorption. ${ }^{[1]}$ The prevalence is almost impossible to determine considering the vast variability of symptoms. According to one estimate there may be eight times as many subclinical or silent celiac cases. ${ }^{[2]}$ In a population -based study, the sero prevalence of undiagnosed Celiac disease in patients aged 50 years or older was $0.8 \% .{ }^{[3]}$ recent reports have indicated increase in prevalence of celiac disease from 2 to 4.5 times. ${ }^{[4]}$

It has been observed that celiac disease can make its first clinical appearance after a major abdominal surgery in previously normal patients. ${ }^{[5]}$ It is not uncommon to find celiac disease in morbidly obese patients. There have been reports of mortality and significant morbidity after bariatric surgery in such patients.[6,7] Performing bariatric surgery in a case of celiac disease therefore involves significant risk and invites special precautions. We here report a case of a patient who is a known case of celiac disease and thalassemia minor who underwent laparoscopic sleeve gastrectomy without worsening of her symptoms of celiac disease.

CASE REPORT: A 53 year old female presented to us with complaints of obesity since pregnancy, Type II Diabetes mellitus since 12 years \& hypertension since 8 years. She was diagnosed to have thalassemia minor 24 years back, but never required blood transfusion for the same. She was diagnosed to have celiac disease 7 years back while evaluating her for recurrent diarrhoea. 


\section{CASE REPORT}

The diagnosis was confirmed with upper GI endoscopy, biopsy and serological tests. She was put on gluten free diet and her symptoms resolved. Her weight was $111 \mathrm{~kg}$ at height of $161 \mathrm{~cm}$ with a BMI of $43.5 \mathrm{~kg} / \mathrm{m}^{2}$. Her HbA1c was $7.3 \%$ and was on insulin since five years along with OHA's. She also had obstructive sleep apnoea.

Patient had tried various supervised weight loss programs in the past without any significant weight loss. Laparoscopic sleeve gastrectomy was planned and risks involved were discussed with her in detail. On evaluation, she was found to have low vitamin B12, vitamin D and ferritin. Her haemoglobin was $8.1 \mathrm{~g} \%$. Deficiencies were corrected pre-operatively. After an Informed consent \& surgical fitness she underwent Laparoscopic sleeve gastrectomy which was fashioned over a $36 \mathrm{~F}$ bougie. Stapling was started $4 \mathrm{~cm}$ proximal to pylorus and staple line reinforced using continuous absorbable suture.

She had an uneventful post-operative course and was discharged on third post-operative day, on a liquid diet. In a follow-up of one year, she had no features suggestive of active celiac disease and is accepting her gluten free diet well. Patient has benefited on all components of her metabolic syndrome. She has stopped all her anti-hypertensives and is on a single OHA with good glycemic control (HbA1c - 5.4). Her haemoglobin has improved from $8.5 \mathrm{~g} \%$ to $11 \mathrm{~g} \%$. At one year follow up she has lost $45 \%$ excess body weight which is comparable to other patients with sleeve gastrectomy.

DISCUSSION: There have been anecdotal reports regarding patients of celiac disease undergoing bariatric procedures but not much is known regarding risks verses benefits. Any major surgery in these patients has the potential to worsen the symptoms. It is hypothesized that trauma of surgery causes abnormal immune reaction of body towards gluten.

The prevalence of the disease is about $1 \%$. The classical clinical picture is of weight loss, diarrhoea and anemia. But presentation can vary widely and disease can make its appearance at any age.[8] Upper GI endoscopy may show loss of duodenal folds, scalloping of folds, mosaic pattern or mucosal fissures. Not all areas of duodenum are equally affected so multiple biopsies must be taken.[9]

Upper GI endoscopy alone can detect about $60 \%$ of the patients harbouring celiac disease.[10] Serological investigations are used for making the diagnosis. Tissue transglutaminase IgA is usually the first test of choice, if it is equivocal then anti-endomysial antibody (IgA) should follow.[11] In a well-controlled disease all tests for celiac disease may be negative and sometimes a once daily gluten meal is prescribed for 2-6 weeks for making diagnosis.

Presence of morbid obesity does not exclude the possibility of celiac disease. Hyperphagia is often present in patients with active disease and $13 \%$ of newly diagnosed cases have been found to be overweight.[12] In a recent report, prevalence of celiac disease in morbidly obese population was found to be equal to the general population. ${ }^{[13]}$ As numbers of bariatric surgeries being performed world-wide increase every year the chances of confronting a known patient of celiac disease are also increasing. The disease may make its first clinical appearance after bariatric surgery and surgeons should keep in mind the possibility of this disease when encountered with suggestive symptoms.

The choice of bariatric procedure in a known case of celiac disease is not standardized. We chose to perform laparoscopic sleeve gastrectomy considering following points in mind. Firstly, the absorptive mechanism is altered in these patients and we wanted to avoid any al-absorptive procedure which would further hamper the absorption of nutrients. Secondly, celiac disease is associated with a significantly increased risk for Non-Hodgkin lymphoma, especially of the T-cell type and primarily localized in the gut.[14] Sleeve gastrectomy does not hinder in the evaluation of small 


\section{CASE REPORT}

bowel. Thirdly, Remission of diabetes and other associated co-morbidities following sleeve gastrectomy are equal to that found with other bariatric procedures like RGB.[15] Lastly, as already discussed, any major abdominal surgery can worsen the disease and sleeve gastrectomy can be performed quickly without much handling of the small bowel.

CONCLUSION: Laparoscopic sleeve gastrectomy can be performed on a known patient of celiac disease without worsening of symptoms. Adequate preoperative patient counseling, intra-operative care and strict postoperative follow-up should be ensured for an uneventful recovery. Restrictive rather than mal absorptive procedures are probably the procedures of choice in such cases \& sleeve gastrectomy, probably is a better restrictive procedure when patient also has metabolic syndrome. Also, the possibility of celiac disease making its first appearance in post-operative bariatric patient should be kept in mind.

\section{REFERENCES:}

1. Ludvigsson JF et al. The Oslo definitions of celiac disease and related terms, Gut. 2013; 62: 43.

2. Cranney A, Rostom A, et al. Consequences of testing for celiac disease. Gastroenterology. 2005; 128: S109-120.

3. Godfrey JD, Branter TL, Brinjikji W, et al. Morbidity and mortality among older individuals with celiac disease. Gastroenterology. 2010; 139 (3): 763-769.

4. Catassi C, Kryszak D, Bhatti B, et al. Natural history of celiac disease autoimmunity in a USA cohort followed since 1974. Ann Med. 2010; 42: 530-538.

5. Bai J, Moron C, et al. Celiac sprue after surgery of the upper gastrointestinal tract. Report of 10 patients with special attention to diagnosis, clinical behaviour \& follow-up. J Clin Gastroenterol. 1991; 13: 521-524.

6. Logan RF, Ferguson A. Jejunal villous atrophy with morbid obesity: death after jejunoileal bypass. Gut. 1982; 23: 999-1004.

7. Owen DA, Thorlakson TK, Walli JE. Celiac disease in a patient with morbid obesity. Arch Intern Med. 1980; 140: 1380-1381.

8. Niveloni $\mathrm{S}$, et al. Clinical pictutre. In Catassi $\mathrm{C}$ et al, eds. The global village of celiac disease (perspectives on celiac disease, volume II). Roma: AJC Press, 2005: 23-44.

9. Nguyen NQ, et al. Current application of confocal endomicroscopy in gastrointestinal disorders. J GastroenterolHepatol. 2008; 23: 1483-1491.

10. Oxentenko AS, Grisolano SW, Murray JA, et al. The insensitivity of endoscopic markers in celiac disease. Am J Gastroenterol 2002; 97: 933-938.

11. Walker MM, Murray JA, Ronkainen J, et al. Detection of celiac disease and lymphocytic enteropathy by parallel serology and histopathology in a population based study. Gastroenterology. 2010; 139: 112-119.

12. Dickey W, Kearney N. Overweight in celiac disease: prevalence, clinical characteristics, and effect of a gluten free diet. Am J Gastroenterol. 2006; 101: 2356-2359.

13. Federico Cuenca-Abente, Fabio Nachman, et al. Diagnosis of celiac disease during pre operativework-up for bariatric disease. ActaGastroenterolLatinoam 2012; 42: 321-324.

14. Catassi C, Bearzi L, et al. Association of celiac disease and intestional lymphomas and other cancers. Gastroenterology. 2005 Apr; 128(4 suppl 1): S79-86. 


\section{CASE REPORT}

15. Keidar A, Hershkop KJ, Marko L, Schweiger C, Hecht L, Bartov N, et al. Roux-en-Y gastric bypass vs sleeve gastrectomy for obese patients with type 2 diabetes: a randomised trial. Diabetologia. 2013 Sep; 56 (9): 1914-8. doi: 10.1007/s00125-013-2965-2. Epub 2013 Jun 14.

\section{AUTHORS:}

1. Ramraj V. N.

2. Tulip Chamany

3. Ramesh M.

\section{PARTICULARS OF CONTRIBUTORS:}

1. Junior Consultant \& Fellow, Department of General, Laparoscopic and Bariatric Surgery, Vikram Hospital, Bangalore, Karnataka.

2. Senior Consultant, Department of General, Laparoscopic and Bariatric Surgery, Vikram Hospital, Bangalore, Karnataka.

3. HOD, Department of General Surgery, Laparoscopic and Bariatric Surgery, Vikram Hospital, Bangalore, Karnataka.
NAME ADDRESS EMAIL ID OF THE CORRESPONDING AUTHOR:

Dr. Ramraj V. N,

\# 655, Burugal Mutt Road,

V. V. Puram,

Bangalore-560004.

Email: ramrajnanak@yahoo.co.in

Date of Submission: 17/10/2014.

Date of Peer Review: 18/10/2014.

Date of Acceptance: 07/11/2014.

Date of Publishing: 13/11/2014. 